\title{
Galectin-3 in septic acute kidney injury: a translational study
}

\author{
Haibing Sun ${ }^{1 \dagger}$, Huiping Jiang ${ }^{1 \dagger}$, Amity Eliaz ${ }^{2}$, John A. Kellum ${ }^{3}$, Zhiyong Peng ${ }^{1 *}$ and Isaac Eliaz ${ }^{4^{*}}$ (D)
}

\begin{abstract}
Background: Galectin-3 (Gal-3) is a pleiotropic glycan-binding protein shown to be involved in sepsis and acute kidney injury (AKI). However, its role has never been elucidated in sepsis-associated AKI (S-AKI). We aimed to explore Gal-3's role and its potential utility as a therapeutic target in S-AKI.

Methods: In 57 patients admitted to the intensive care unit (ICU) with sepsis, serum Gal-3 was examined as a predictor of ICU mortality and development of AKI. In a rat model of S-AKI induced by cecal ligation and puncture (CLP), 7-day mortality and serum Gal-3, Interleukin-6 (IL-6), and creatinine were examined at 2, 8, and 24 hours (h) post-CLP. Two experimental groups received the Gal-3 inhibitor modified citrus pectin (P-MCP) at $400 \mathrm{mg} / \mathrm{kg} /$ day and $1200 \mathrm{mg} /$ $\mathrm{kg} /$ day, while the control group received water only ( $n=18$ in each group).
\end{abstract}

Results: Among 57 patients, 27 developed AKI and 8 died in the ICU. Serum Gal-3 was an independent predictor of AKI $(\mathrm{OR}=1.2[95 \% \mathrm{Cl} 1.1-1.4], p=0.01)$ and ICU mortality $(\mathrm{OR}=1.4[95 \% \mathrm{Cl} 1.1-2.2], p=0.04)$ before and after controlling for age, AKI, and acute physiology and chronic health evaluation (APACHE II) score. In the CLP rat experiment, serum Gal-3 peaked earlier than IL-6. Serum Gal-3 was significantly lower in both P-MCP groups compared to control at $2 \mathrm{~h}$ post-CLP (400 mg: $p=0.003 ; 1200 \mathrm{mg}: p=0.002)$, and IL-6 was significantly lower in both P-MCP groups at all time points with a maximum difference at $24 \mathrm{~h}$ post-CLP (400 mg: $p=0.015 ; 1200 \mathrm{mg}: p=0.02)$. In the Gal-3 inhibitor groups, 7-day mortality was significantly reduced from $61 \%$ in the control group to $28 \%$ (400 mg P-MCP: $p=0.03$ ) and 22\% (1200 mg P-MCP: $p=0.001$ ). Rates of AKI per RIFLE criteria were significantly reduced from $89 \%$ in the control group to 44\% in both P-MCP groups (400 mg: $p=0.007 ; 1200 \mathrm{mg}: p=0.007$ ).

Conclusions: This translational study demonstrates the importance of Gal-3 in the pathogenesis of S-AKI, and its potential utility as a therapeutic target.

Keywords: Galectin-3, Sepsis, Acute kidney injury

\section{Introduction}

Sepsis-associated acute kidney injury (S-AKI) is common among critically ill patients [1-4]. S-AKI is associated with an increased risk of Intensive Care Unit (ICU) or hospital mortality $[5,6]$. Further, the individual

\footnotetext{
*Correspondence: pengzy5@hotmail.com; isaac.eliaz@gmail.com

${ }^{\dagger}$ Haibing Sun and Huiping Jiang have contributed equally to this

manuscript and share the first authorship

1 Department of Critical Care Medicine, Zhongnan Hospital, Wuhan

University, Wuhan, Hubei Province, China

${ }^{4}$ Amitabha Medical Center, Santa Rosa, CA, USA

Full list of author information is available at the end of the article
}

syndromes of sepsis and AKI each render a patient more vulnerable to the other [7]. Available evidence does not suggest that standard renal replacement therapies improve outcomes beyond control of fluid balance and azotemia [8]. Thus, novel approaches are necessary to prevent and treat S-AKI.

Sepsis and S-AKI result from a dysregulated immune response [9]. Foreign antigens bind to innate immune receptors and subsequently activate inflammasome components, ultimately leading to the elevated release of proinflammatory cytokines both systemically and locally [9]. The resultant cytokine storm is associated with increased 
levels of Interleukin-6 (IL-6) [10]. Multiple reports indicate that IL-6 is an excellent biomarker of severity and a prognostic indicator in patients with sepsis [11-15]. Findings pertaining to the therapeutic utility of IL-6 inhibition in S-AKI remain mixed $[16,17]$, suggesting that processes upstream of IL- 6 may be responsible for triggering the deleterious effects in sepsis and S-AKI.

Galectin-3 (Gal-3) is a pleiotropic glycan-binding protein involved in numerous physiological and pathological events [18], including those that relate to immune function [19]. Epidemiologic studies have found an association between serum Gal-3 level and risk of sepsis [20-22] as well as development of chronic kidney disease (CKD) [23-25]. Pertinent findings show that serum Gal-3 predicts 30-day all-cause mortality in sepsis [26], preoperative serum Gal-3 predicts AKI after cardiac surgery [27], and serum Gal-3 at ICU discharge is associated with severity of AKI [28]. However, no previous study has examined the relationship between serum Gal-3 at the time of admission and the subsequent development of AKI in patients with sepsis. Additionally, the temporal relationship between Gal-3 and IL-6 in the pathophysiology of S-AKI has never before been explored.

Prior murine studies have demonstrated the importance of Gal-3 in the pathogenesis of sepsis $[29,30]$ and kidney disease [31, 32], including AKI [28, 33-36]. Pharmacologic inhibition of Gal-3 has ameliorated nephropathy induced by renal ischemia-reperfusion (IR) [28], unilateral ureteral obstruction [29], folic acid [34], hypertension [37, 38], aldosterone [39], unilateral nephrectomy [40], obesity [41], aortic stenosis [41], and cisplatin [42]. However, no murine experiment has evaluated the relationship between Gal-3 and AKI in sepsis.

Here, we present a translational study of serum Gal-3 in sepsis and S-AKI. We aimed to explore the role of Gal-3 in the pathophysiology of S-AKI and its potential utility as a therapeutic target. We examined patients admitted to the ICU with sepsis and determined whether serum Gal-3 levels predicted subsequent development of AKI and ICU mortality. In a rat model of sepsis induced by cecal ligation and puncture (CLP), we evaluated the role of Gal-3 in the pathogenesis of S-AKI, as well as the potential utility of Gal-3 as a therapeutic target. We studied the effect of an oral Gal-3 inhibitor, modified citrus pectin, on S-AKI occurrence, mortality, and levels of serum Gal-3, IL-6, and creatinine, as well as the temporal relationship between the rise of serum Gal-3 and IL-6.

\section{Methods}

\section{Patient study}

A prospective observational study was conducted with the approval of the Ethics Committee of Zhongnan Hospital of Wuhan University at the general ICU of
Zhongnan Hospital of Wuhan University, Hubei Province, China. From January 1, 2019 to October 31, 2019, consecutive patients were enrolled following a diagnosis of sepsis according to the Third International Consensus (Sepsis-3) Definitions [43]. Patients with pre-existing $\mathrm{AKI}, \mathrm{CKD}$, renal replacement therapy, end-stage renal disease, malignancy, or organ transplantation were excluded from the study. Patients without a consent form, less than 18 years old, or over 80 years old were also excluded. An acute physiology and chronic health evaluation (APACHE II) assessment was also performed [44]. The two primary outcomes were survival in the ICU and development of subsequent AKI.

\section{Serum biochemical measurements}

A blood sample was obtained from patients within 6 hours (h) of admission to the ICU. Serum Gal-3 was measured by the human Gal-3 enzyme-linked immunosorbent assay (ELISA) Kit (BG Medicine, Corgenix, Inc., Broomfield, $\mathrm{CO}$, USA; detection range: $1.4 \mathrm{ng} / \mathrm{ml}$ to $94.8 \mathrm{ng} / \mathrm{ml})$, and serum creatinine $(\mathrm{Cr})$ was measured using AU5831 Clinical Chemistry Analyzers (Beckman Coulter, Inc. Brea, CA, USA). In addition, serum neutrophil gelatinase-associated lipocalin (NGAL) and cystatin $\mathrm{C}(\mathrm{CysC})$ were measured with ELISA kits (Proteintech, Rosemont, IL, USA) according to the manufacturer`s instructions. Procalcitonin (PCT) was also measured using the ELFA (Enzyme-Linked Fluorescent Assay) technique by VIDAS ${ }^{\circledR} \mathrm{B} \cdot \mathrm{R} \cdot \mathrm{A} \cdot \mathrm{H} \cdot \mathrm{M} \cdot \mathrm{S} \quad \mathrm{PCT}^{\mathrm{TM}}$ (bioMérieux, Inc., Marcy-l'Étoile, France).

\section{Evaluation of renal function and survival}

AKI was evaluated according to Kidney Disease: Improving Global Outcomes (KDIGO) clinical practice guidelines based on serum $\mathrm{Cr}$ criteria [45]. In addition, patient survival during ICU stay was evaluated.

\section{Animal study}

Male adult (weight 400-600 g) Sprague-Dawley rats were purchased from the Center for Animal Experiment of Wuhan University. All animals were housed in individually ventilated cages and had free access to water and food. All performed procedures were previously reviewed and approved by the Animal Care and Use Committee of Wuhan University.

\section{Cecal ligation and puncture model}

CLP was performed with a predetermined 25\% ligated length of cecum. Following ligation, the cecum was punctured twice using a 20-gauge needle inferior to the ileocecal valve. The abdomen was then closed and $20 \mathrm{ml} / \mathrm{kg}$ of prewarmed saline was administered subcutaneously as 
fluid resuscitation. Rats were returned to their cages and allowed food and water ad libitum.

\section{Animal experimental protocol}

The animal study included three groups (Fig. 1). All rat groups underwent CLP. Two intervention groups were administered low molecular weight modified citrus pectin (P-MCP) (PectaSol- $\mathrm{C}^{\circledR}$, EcoNugenics, Santa Rosa, CA, USA) in drinking water for seven days prior to CLP. $\mathrm{P}-\mathrm{MCP}$ is a dietary supplement comprised of low molecular weight pectin, which directly inhibits Gal-3 by binding to the carbohydrate recognition domain of Gal-3 [46]. The pectin is derived from the pith of citrus peels, after which it is enzymatically treated to yield pectin fibers with a molecular weight less than $15 \mathrm{kDa}$ and less than $5 \%$ esterification [46]. The effect of P-MCP has been validated in multiple animal models of AKI [36, 38, 39, 41, 42].

The first intervention group $(n=18)$ received P-MCP at $400 \mathrm{mg} / \mathrm{kg} /$ day, while the second intervention group $(n=18)$ received P-MCP at $1200 \mathrm{mg} / \mathrm{kg} /$ day. The control group $(n=18)$ was not provided with P-MCP prior to CLP and received water ad libitum. P-MCP was not provided to any group following the CLP procedure.

\section{Serum biochemical measurements}

Blood $(1.0 \mathrm{ml})$ was drawn from the jugular vein at $24 \mathrm{~h}$ prior to CLP (as baseline), and at 2, 8, and $24 \mathrm{~h}$ postCLP. Serum was collected using EDTA as an anticoagulant. Samples were centrifuged for $15 \mathrm{~min}$ at $1000 \times g$ at $2-8{ }^{\circ} \mathrm{C}$ within $30 \mathrm{~min}$ of collection. The supernatant was collected for assaying.

Serum Gal-3 levels were measured at baseline, 2, 8, and $24 \mathrm{~h}$ post-CLP, using an enzyme-linked immunosorbent assay (ELISA) (Lifespan Biosciences, Seattle, WA, USA; detection range: $0.156 \mathrm{ng} / \mathrm{ml}$ to $10 \mathrm{ng} / \mathrm{ml}$ ), and serum IL-6 level was measured at baseline, 2,8 , and $24 \mathrm{~h}$ postCLP, using an ELISA (R\&D Systems, Minneapolis, MN, USA). Additionally, rat serum $\mathrm{Cr}$ levels were measured to assess renal function using a $\mathrm{Cr}$ assay kit (Nanjing Jiancheng Bioengineering Institute, Nanjing, China).

\section{Evaluation of renal function and survival rate}

Serum $\mathrm{Cr}$ was measured at baseline, 2, 8, and $24 \mathrm{~h}$ postCLP to assess renal function using a $\mathrm{Cr}$ enzymatic assay kit. AKI occurrence was determined by Risk, Injury, Failure, Loss of kidney function, and End-stage kidney disease (RIFLE) criteria at $24 \mathrm{~h}$ post-CLP. Per RIFLE criteria, AKI was defined as Cr level at least $150 \%$ of baseline at $24 \mathrm{~h}$, and severity was categorized as risk (RIFLE-R), injury (RIFLE-I), and failure (RIFLE-F) according to $\mathrm{Cr}$ level at $150 \%, 200 \%$, and $300 \%$ of baseline respectively at $24 \mathrm{~h}[47,48]$. Survival was evaluated at 7 days post-CLP.

\section{Statistical analysis}

All numerical data were expressed as mean \pm standard error of the mean (SEM) or median and interquartile range. Statistical $p<0.05$ was considered significant. Sample means were compared between groups using two-tailed t-tests and analysis of variance (ANOVA), and within-group differences were analyzed using the Wilcoxon signed-rank test. Additionally, Pearson's chi-squared test was used to evaluate for associations between categorical variables. Survival analysis was conducted using Kaplan-Meier analysis, and mortality in each group was compared using the log-rank test.

Multivariate logistic regression was performed to analyze Gal-3 as an independent predictor of death with and without controlling for age, AKI, and APACHE II score. Multivariate logistic regression was also used to evaluate

- Male adult (weight 400-600g) Sprague-Dawley rats

- 18 rats in each group

- CLP was performed with a predetermined $25 \%$ ligated length of cecum

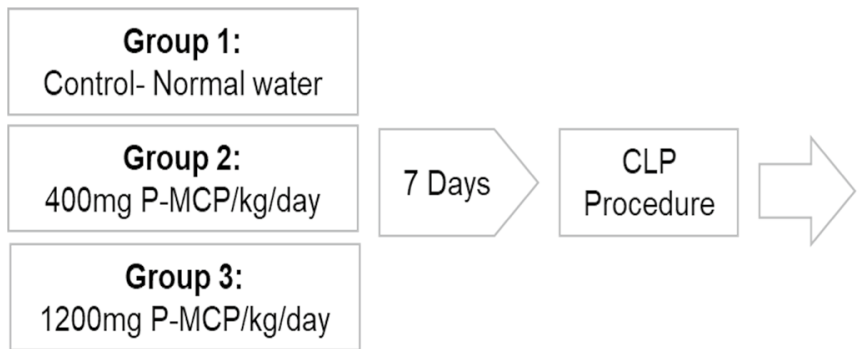

Blood collection: 0 hrs, 2 hrs, 8 hrs, 24 hrs Measurements: Serum creatinine, IL-6, galectin-3

Fig. 1 CLP experimental strategy. All rats underwent CLP. Control group $(n=18)$ received normal drinking water, while two intervention groups received a Gal-3 inhibitor, PMCP, at 400 mg/kg/d and 1200 mg/kg/d 7 d prior to CLP. Following CLP, blood was drawn at baseline, 2,8 , and $24 \mathrm{~h}$ post-CLP for serum biochemical measurements 
Gal-3 as an independent predictor of AKI with and without adjusting for age and APACHE II score. Area under the receiver operating characteristic curve (AUC-ROC) was estimated to evaluate the performance of Gal-3 as a predictor of S-AKI and death in ICU patients [49]. Statistical analyses were performed using $\mathrm{R}$ software and Microsoft 365 Excel data analysis software.

\section{Results}

\section{Patient characteristics}

The study sample included 57 patients who were admitted to the ICU with a diagnosis of sepsis. Table 1 summarizes patient characteristics at the time of admission and mean serum Gal-3 levels, as well as additional serum biomarkers CysC, NGAL, and PCT levels. There was no significant difference in mean age between patients that developed S-AKI and patients that did not develop S-AKI following ICU admission (age: $60.6 \pm 1.6$ years vs. $59 \pm 2.0$ years, $p=0.53$ ). APACHE II score was significantly higher among patients that developed S-AKI as compared to patients that did not $(18.6 \pm 1.2$ vs $15.2 \pm 1.1, p<0.05)$.

\section{Serum Galectin-3, AKI, and survival}

Of the 57 patients admitted to the ICU, 27 (47\%) subsequently developed S-AKI. Additionally, 8 patients (14\%) died during the ICU stay: 6 were in the S-AKI group and 2 were in the non-AKI group. Mean serum Gal-3 level was significantly higher among patients that developed subsequent S-AKI as compared to patients that did not develop S-AKI $(11.2 \pm 1.6 \mathrm{ng} / \mathrm{ml}$ vs. $5.3 \pm 0.5 \mathrm{ng} / \mathrm{ml}$; $p=0.002$ ) (Fig. 2a). Mean serum Gal-3 level was also significantly higher among patients that died as compared to patients that did not die $(18.7 \pm 3.6 \mathrm{ng} / \mathrm{ml}$ vs. $6.4 \pm 0.7 \mathrm{ng} /$ $\mathrm{ml} ; p=0.01$ ) (Fig. 2b). Using multivariate logistic regression, serum Gal-3 was associated with an increased odds of death before and after adjusting for age, AKI occurrence, and APACHE II score $(\mathrm{OR}=1.4[95 \% \mathrm{CI}$ 1.1-2.2], $p=0.04)$. Serum Gal-3 was also associated with an increased odds of AKI before and after adjusting for age and APACHE II score (OR $=1.2$ [95\% CI 1.1-1.4], $p=0.01$ ). The AUC-ROC for serum Gal-3 predicting subsequent AKI was 0.73, and the AUC-ROC for serum Gal-3 predicting ICU mortality was 0.91 (Fig. 2c).

\section{Rat Cecal ligation and puncture model}

In total, 54 animals underwent the CLP procedure: 18 rats in the control group, and 18 rats in each P-MCPtreated group.

\section{Galectin-3}

Differences in serum Gal-3 concentrations between control and P-MCP-treated rats are shown in Fig. 3. Baseline serum values were not significantly different among the three rat groups $(F=3.2, p=0.15)$. In both P-MCPtreated groups, mean serum Gal-3 levels were significantly lower than control at $2 \mathrm{~h}$ post procedure $(400 \mathrm{mg}$ P-MCP: $0.83 \pm 0.05 \mathrm{ng} / \mathrm{ml}$ vs $1.63 \pm 0.22 \mathrm{ng} / \mathrm{ml}, p=0.003$; $1200 \mathrm{mg}$ P-MCP: $0.82 \pm 0.08 \mathrm{ng} / \mathrm{ml}$ vs $1.63 \pm 0.22 \mathrm{ng} / \mathrm{ml}$, $p=0.001)$. Serum Gal-3 levels in all groups peaked at $2 \mathrm{~h}$ post-CLP and were significantly higher than their respective baseline values (control: $p=0.0001 ; 400 \mathrm{mg} \mathrm{P}-\mathrm{MCP}$ : $p=0.001 ; 1200 \mathrm{mg}$ P-MCP: $p=0.004)$. Gal-3 levels in all three groups subsided rapidly and were no longer significantly elevated at $8 \mathrm{~h}$ post CLP compared to their respective baseline values. The AUC-ROC for serum Gal-3 predicting subsequent AKI was 0.75, and the AUC-ROC for serum Gal-3 predicting mortality was 0.88 (Fig. 4a).

\section{Interleukin-6}

Differences in serum IL-6 concentrations between control and P-MCP-treated rats are shown in Fig. 5. Baseline values were not significantly different among the three groups $(\mathrm{F}=3.2, p=0.56)$. Concentrations of serum IL-6

Table 1 Characteristics of patients at ICU admission

\begin{tabular}{|c|c|c|c|c|}
\hline Variable & All patients $(n=57)$ & $\begin{array}{l}\text { Patients without subsequent AKI } \\
(n=30)\end{array}$ & $\begin{array}{l}\text { Patients with subsequent AKI } \\
(n=27)\end{array}$ & $P$ value \\
\hline Age (years) & $59(53-66)$ & $59(53-66.8)$ & $61(55-66)$ & 0.53 \\
\hline Female sex, $n(\%)$ & $32(56)$ & $18(60)$ & $14(52)$ & 0.73 \\
\hline ICU stay (days) & $13(9-15)$ & $11(8.3-13)$ & $15(11.5-19.5)$ & $<0.001$ \\
\hline APACHE II score & $16(12-21)$ & $14(11-17)$ & $20(13.5-23)$ & $<0.05$ \\
\hline Serum Gal-3 (ng/ml) & $5.7(3.6-8.9)$ & $4.2(3.5-7)$ & $7.9(4.7-16.6)$ & 0.002 \\
\hline Serum CysC $(\mu \mathrm{g} / \mathrm{ml})$ & $1.5(1.1-2.2)$ & $1.2(0.9-1.5)$ & $2(1.7-4.1)$ & 0.002 \\
\hline Serum NGAL (ng/ml) & $302.9(175.3-514.2)$ & $243.4(170.6-421.9)$ & $430(215-561)$ & 0.406 \\
\hline Serum PCT (ng/ml) & $11.2(3.1-52.4)$ & $7.7(2.9-27.3)$ & $32.6(3.7-91)$ & 0.007 \\
\hline
\end{tabular}

Characteristics of patients in AKI and non-AKI groups. Characteristics were compared using chi-square tests or two-tailed t-tests. AKI acute kidney injury, APACHE II acute physiology and chronic health evaluation II, CysC cystatin C, Gal-3 galectin-3, ICU intensive care unit, NGAL neutrophil gelatinase-associated lipocalin, PCT procalcitonin 

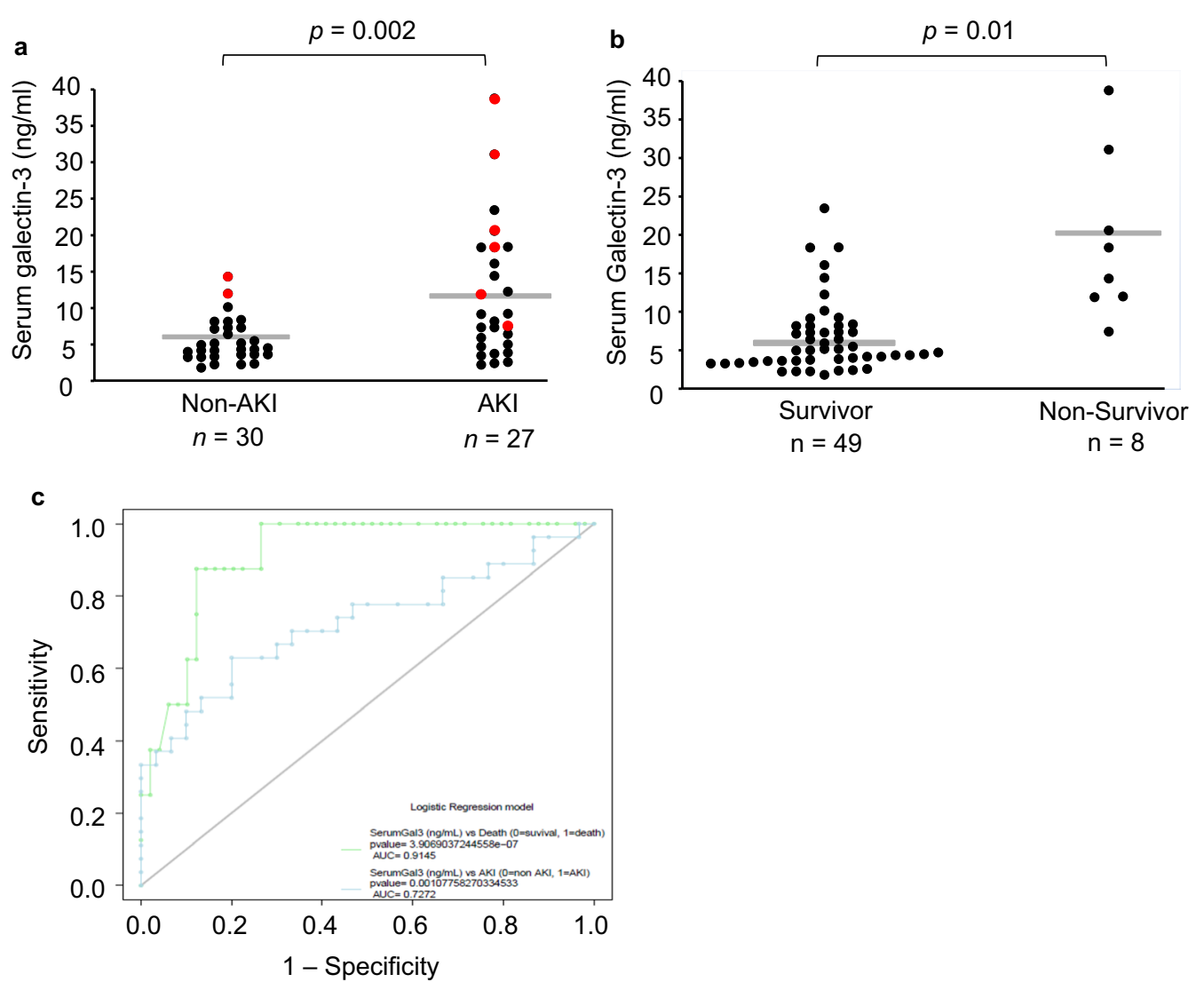

Fig. 2 Serum galectin-3 levels at ICU admission predict subsequent acute kidney injury and ICU mortality among patients. Means are shown by the gray horizontal bars and displayed numerically above the corresponding columns. a Serum galectin-3 levels in AKI vs non-AKI groups following ICU admission (11.2 $\pm 1.6 \mathrm{ng} / \mathrm{ml}$ vs. $5.3 \pm 0.5 \mathrm{ng} / \mathrm{ml}, p=0.002$ ). Red dots represent data from non-survivors, while black dots represent data from survivors. b Serum galectin-3 levels in survivor vs non-survivor groups following ICU admission ( $18.7 \pm 3.6 \mathrm{ng} / \mathrm{ml} \mathrm{vs.} 6.4 \pm 0.6 \mathrm{ng} / \mathrm{ml}, p=0.0002)$. $\mathbf{c}$ Area under the receiver operating characteristic curves for serum galectin-3 in survival (green curve) and galectin-3 in AKI (blue curve)

in both P-MCP-treated groups were significantly lower than control values at all post-CLP time points, with the maximum difference at $24 \mathrm{~h}$ post-CLP (400 mg P-MCP: $468.0 \pm 89.5 \mathrm{pg} / \mathrm{ml}$ vs $1344.5 \pm 1103.4 \mathrm{pg} / \mathrm{ml}, p=0.015$; $1200 \mathrm{mg}$ P-MCP: $458.8 \pm 251.9 \mathrm{pg} / \mathrm{ml}$ vs $1344.5 \pm 1103.4$, $p=0.02$ ) (Fig. 5). Serum IL-6 in the control group increased over time and peaked at $24 \mathrm{~h}$ post-CLP $(3,344.5 \pm 1,103.4 \mathrm{pg} / \mathrm{ml})$. In both Gal-3 inhibitor groups, IL-6 levels decreased between 8 and $24 \mathrm{~h}$ post-procedure. The reduction in IL- 6 levels between 8 and 24 h postCLP was statistically significant in the $1200 \mathrm{mg}$ P-MCP group only (631 [IQR 494.7-828.2] pg/ml vs 187.2 [IQR $156.5-272.6] \mathrm{pg} / \mathrm{ml}, p=0.006)$. The AUC-ROC for serum IL-6 predicting subsequent AKI was 0.74, and the AUCROC for serum IL-6 predicting ICU mortality was 0.81 (Fig. 4b).

\section{Creatinine}

Differences in serum $\mathrm{Cr}$ concentrations between control and P-MCP-treated rats are shown in Fig. 6. Baseline values were not significantly different between the three groups $(\mathrm{F}=3.2, p=0.54)$. Serum $\mathrm{Cr}$ concentration in the $1200 \mathrm{mg}$ P-MCP-treated group was significantly lower than control at all time points post-CLP, reaching a peak difference at $24 \mathrm{~h}$ post-procedure $(51.8 \pm 6.7 \mu \mathrm{mol} / \mathrm{l} \mathrm{vs}$ $104.6 \pm 18.8 \mu \mathrm{mol} / \mathrm{l}, p=0.016)$. Serum $\mathrm{Cr}$ concentration in the $400 \mathrm{mg} \mathrm{P}-\mathrm{MCP}$-treated group was significantly lower than control group at $2 \mathrm{~h}$ and $24 \mathrm{~h}$ post-CLP $(2 \mathrm{~h}$ : $26.3 \pm 0.9 \mu \mathrm{mol} / \mathrm{l}$ vs $31.3 \pm 1.6 \mu \mathrm{mol} / \mathrm{l}, p=0.009 ; 24 \mathrm{~h}$ : $53.5 \pm 4.2 \mu \mathrm{mol} / \mathrm{l}$ vs $104.6 \pm 18.8 \mu \mathrm{mol} / \mathrm{l}, p=0.005)$.

\section{AKI}

The percent of animals that developed AKI at $24 \mathrm{~h}$ postCLP in the control and P-MCP-treated groups are shown in Fig. 7. As determined by RIFLE criteria, 89\% (16) of rats in the control group developed AKI, while 44\% (8) of rats developed AKI in the $400 \mathrm{mg}$ P-MCP group and 44\% (8) developed AKI in the $1200 \mathrm{mg}$ P-MCP group. There was a statistically significant difference in AKI rate between the control group and both the $400 \mathrm{mg}$ 


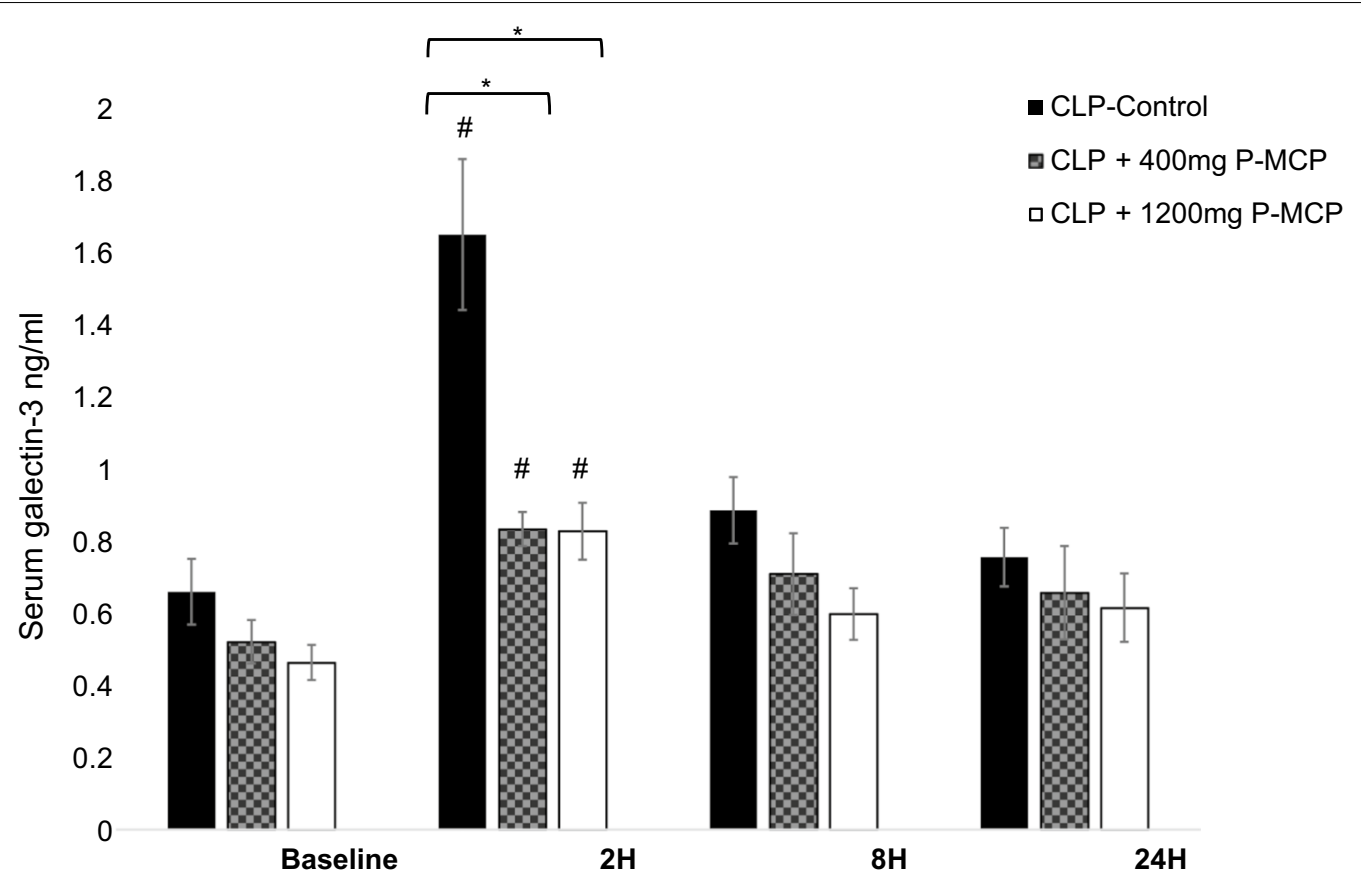

Fig. 3 Serum galectin-3 levels with and without P-MCP pretreatment at baseline, $2 \mathrm{~h}, 8 \mathrm{~h}$, and $24 \mathrm{~h}$ post-CLP in a rat CLP model. ${ }^{*}$ indicates $p<0.05$ for comparison between control group and P-MCP-treatment group. \# indicates $p<0.05$ for within group comparison to baseline value
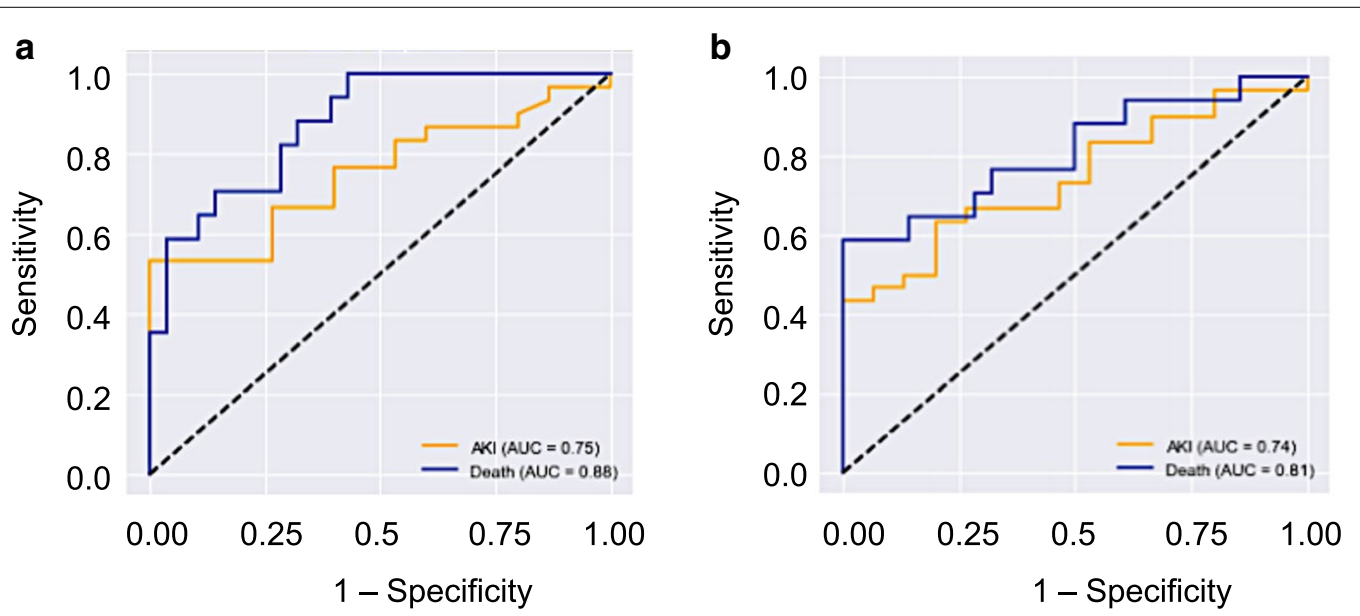

Fig. 4 Serum galectin-3 and IL-6 predict AKI and death in a rat CLP model. a Area under the receiver operating characteristic curve for serum galectin-3 in AKI (yellow curve) and mortality (blue curve). b Area under the receiver operating characteristic curve for IL-6 in AKI (yellow curve) and mortality (blue curve)

P-MCP group $(p=0.007)$ and $1200 \mathrm{mg}$ P-MCP group $(p=0.007)$. In the control group, $8(44 \%)$ rats were classified as RIFLE-R, 2 (11\%) rats were RIFLE-I, and 6 (33\%) rats were RIFLE-F. In the $400 \mathrm{mg}$ P-MCP group, 1 (6\%) rat was classified as RIFLE-R, 4 (22\%) rats were RIFLE-I, and $3(17 \%)$ rats were RIFLE-F. In the $1200 \mathrm{mg}$ P-MCP group, $1(6 \%)$ rat was classified as RIFLE-R, $4(22 \%)$ rats were RIFLE-I, and 3 (17\%) rats were RIFLE-F.

\section{Survival}

Survival data are shown in Fig. 8. Each group began with 18 rats prior to CLP. At 7 days post-CLP, 11 (61\%) rats had died in the control group compared to $5(28 \%)$ rats in the $400 \mathrm{mg} \mathrm{P}-\mathrm{MCP}$ group and 4 (22\%) rats in the $1200 \mathrm{mg}$ P-MCP group. Mortality was significantly lower in both P-MCP treated groups as compared to controls (400 mg P-MCP: $p=0.03$; 1200 mg P-MCP: $p=0.001)$. 

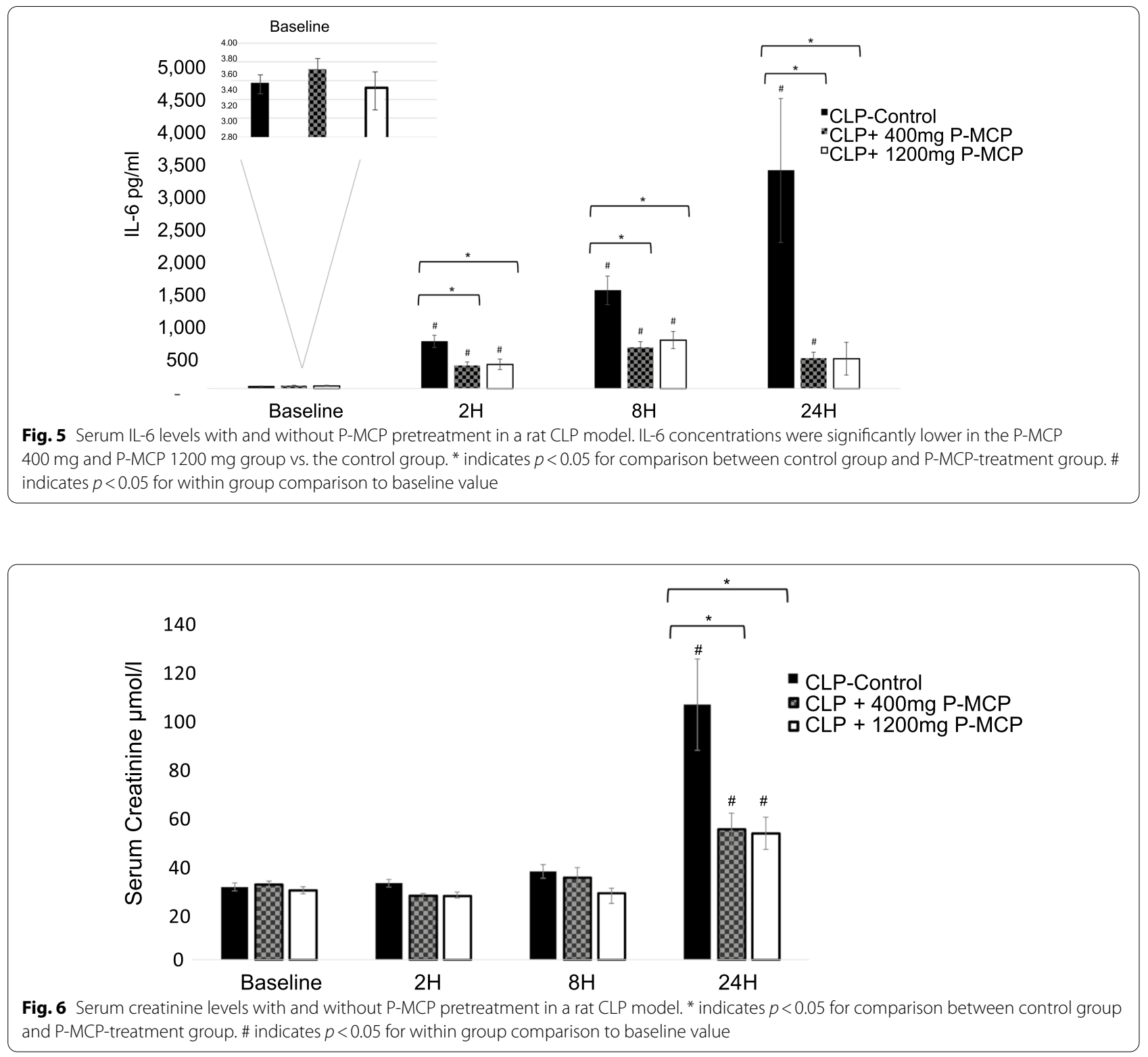

\section{Discussion}

In this translational study, we evaluated the role of Gal-3 in sepsis and S-AKI. We found that elevated Gal-3 levels at ICU admission predicted S-AKI and mortality in patients with sepsis, while inhibition of Gal-3 in a CLP rat model resulted in a statistically significant reduction in S-AKI and mortality. Together, these findings suggest that Gal-3 plays an important role in the pathophysiology of S-AKI and sepsis mortality.

In patients admitted to the ICU with sepsis, elevated serum Gal-3 levels at admission predicted ICU mortality. Our findings are consistent with other clinical research in which serum Gal-3 levels predicted 30-day all-cause mortality in sepsis [26], as well as murine experiments demonstrating the important role of Gal-3 in sepsis pathogenesis and mortality [27, 30]. Our findings suggest that serum Gal-3 may serve as a prognostic indicator in sepsis.

We also found that serum Gal-3 levels obtained at ICU admission were associated with subsequent $\mathrm{AKI}$, as were two previously studied biomarkers of kidney injury, CysC and PCT [50-52]. Further, Gal-3 levels predicted subsequent development of S-AKI after controlling for age and APACHE II score. This is the first report of such a finding in patients with sepsis. It is consistent with previous findings that preoperative serum Gal-3 predicts AKI after 


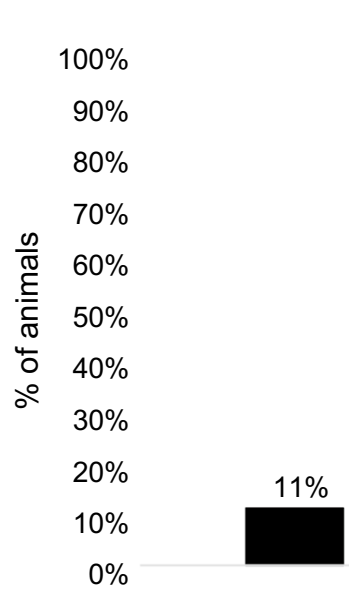

NO AKI
Control

$\square$ 400mg P-MCP

$\square 1200 \mathrm{mg}$ P-MCP

Fig. 7 Acute kidney injury occurrence with and without P-MCP pretreatment in a rat CLP model. Percent AKI with or without P-MCP pretreatment per RIFLE criteria. Within the control group, 16 (89\%) rats developed AKI. In each P-MCP group (400 mg and 1200 mg), 8 (44\%) rats developed AKI

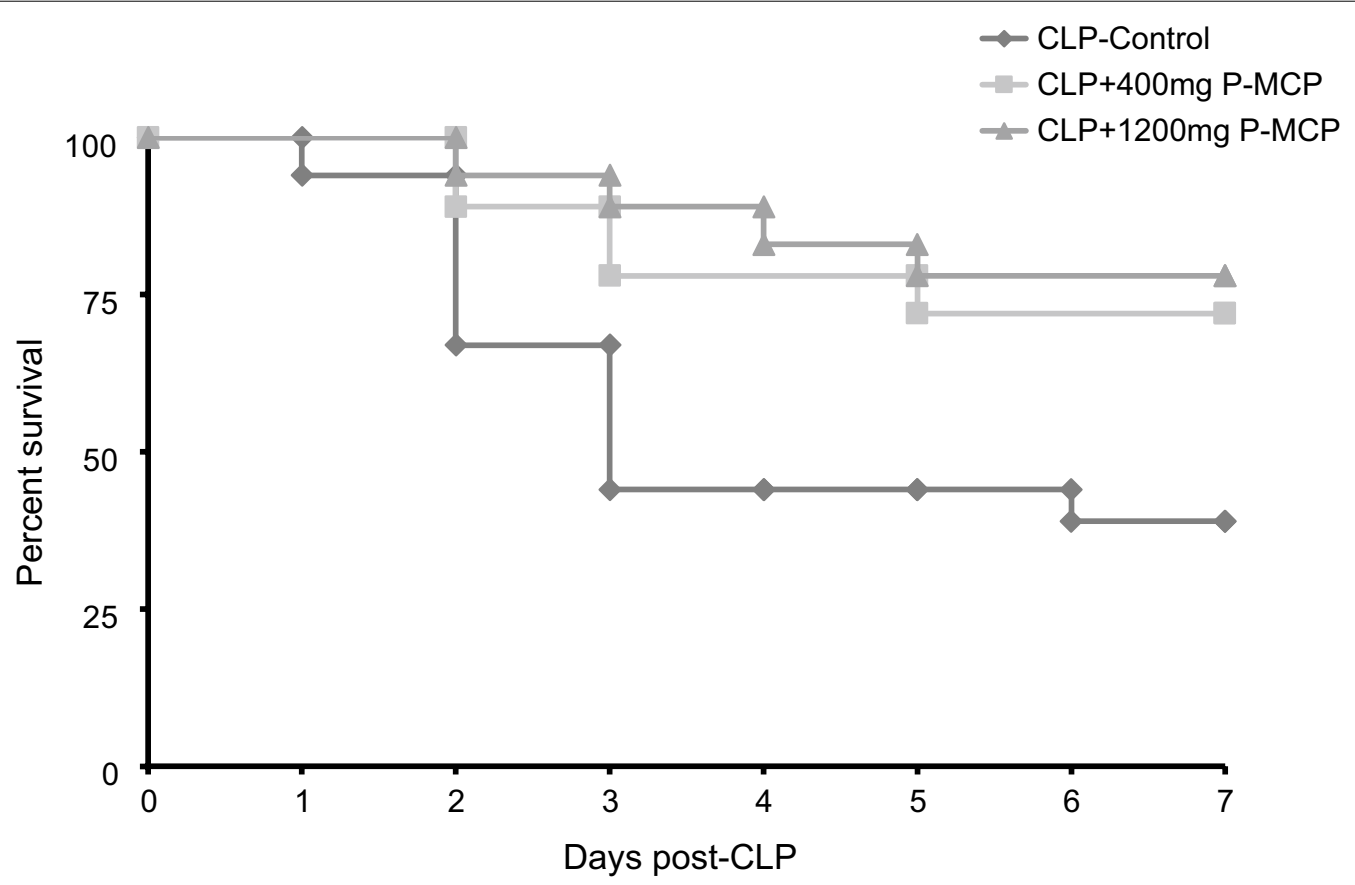

Fig. 8 Survival curves with and without P-MCP pretreatment in a rat CLP model. Each group started with 18 rats prior to CLP procedure. By day 7 , $11(61 \%)$ rats had died in the control group, compared to only $5(28 \%)$ rats in the $400 \mathrm{mg}$ P-MCP group $(p=0.03)$ and $4(22 \%)$ rats in the $1200 \mathrm{mg}$ P-MCP group ( $p=0.001)$

cardiac surgery [27], and that Gal-3 at the time of ICU discharge is associated with severity of AKI [28]. Our findings are also consistent with various murine experiments, which demonstrate that Gal-3 plays a role in the pathophysiology of AKI secondary to various insults [28, 33-36]. In our patient study, 6 of the 8 observed deaths were in patients who had developed S-AKI, suggesting that the increased mortality seen in those with high Gal-3 levels may be mediated, at least in part, by impaired renal function [53]. While there was an association between Gal-3 and AKI, the predictive ability of Gal-3 in the detection of AKI was lower than that of mortality. Notably, the patient study was limited by its observational nature, small sample size, and low mortality rate. The 
findings demonstrate an association of Gal-3 with both mortality and AKI, and warrant further evaluation of the role of Gal-3 in S-AKI and sepsis mortality.

In a CLP rat model, we found that administration of a Gal-3 inhibitor prior to CLP significantly reduced mortality and S-AKI rate in both P-MCP-treated groups. Inhibition of Gal-3 also resulted in a significant reduction in Gal-3 and IL-6 levels. The difference between IL-6 levels in the control and P-MCP-treated groups increased over time, reaching the greatest difference at $24 \mathrm{~h}$ postCLP. Prior studies have also reported attenuation of IL-6 levels with Gal-3 knock out or Gal-3 inhibition [28, 29, $35,37]$.

In the control group, serum Gal-3 levels peaked earlier than serum IL-6: Gal-3 levels peaked at $2 \mathrm{~h}$ post-CLP and fell to near-baseline by $8 \mathrm{~h}$, while IL- 6 continued to rise throughout the entire $24 \mathrm{~h}$ post-procedure period. Comparatively, in the Gal-3 inhibitor groups, IL-6 levels decreased between 8 and $24 \mathrm{~h}$ post-procedure. Compared to controls, the decrease in IL- 6 between 8 and $24 \mathrm{~h}$ was statistically significant in the $1200 \mathrm{mg}$ P-MCP group only. Together, these findings suggest that serum Gal-3 release may precede the rise of IL-6 in the inflammatory cascade. Additionally, P-MCP-mediated Gal-3 inhibition may exert its effect in a dose dependent manner. At higher doses, Gal-3 inhibition may cause IL-6 levels to drop at an earlier time point.

Given the important role of IL- 6 in the inflammatory cascade, these preliminary findings suggest that Gal-3 may serve as an upstream mediator of the "cytokine storm" in sepsis and S-AKI [54]. Study limitations included small sample sizes, as well as limited follow-up time to monitor $\mathrm{Cr}$ rise. Additionally, given our aim to compare mortality among CLP groups, histological evaluation of renal tissue was not possible.

In humans, elevations in serum Gal-3 may persist for longer durations. In a study by Prud'homme et al., 645 patients with AKI during their ICU stay demonstrated elevated serum Gal-3 levels at discharge [28]. Further, Gal-3 levels at discharge were increasingly elevated with increased severity of AKI [28]. Given these findings, Gal-3 may continue to play a role in the progression of AKI past the 2 to $8 \mathrm{~h}$ range detected in our rat model. Our findings warrant further investigation of the potential therapeutic utility of Gal-3 inhibition or removal in the prevention and treatment of S-AKI.

\section{Conclusion}

This translational study demonstrates the important role of Gal-3 in the pathogenesis of S-AKI, as well as its potential utility as a therapeutic target. Further studies, including randomized trials, are warranted to examine the role of Gal-3 as a therapeutic target in the treatment of sepsis and S-AKI.

\section{Abbreviations}

AKI: Acute kidney injury; APACHE II: Acute physiology and chronic health evaluation; AUC-ROC: Area under the receiver operating characteristic; CLP: Cecal ligation and puncture; CKD: Chronic kidney disease; $\mathrm{Cr}$ : Creatinine; CysC: Cystatin C; ELFA: Enzyme-linked fluorescent assay; ELISA: Enzyme-linked immunosorbent assay; Gal-3: Galectin-3; IL-6: Interleukin-6; ICU: Intensive care unit; KDIGO: Kidney disease: improving global outcomes; P-MCP: Pectasol modified citrus pectin; NGAL: Neutrophil gelatinase-associated lipocalin; PCT: Procalcitonin; RIFLE: Risk, injury, failure, loss of kidney function, and end-stage kidney disease; S-AKI: Sepsis-associated AKI.

\section{Acknowledgements}

The authors would like to thank Anat Stern, John Trepanowski, Dale Cumming, and Barry Wilk for their help in preparing the manuscript.

\section{Authors' contributions}

$\mathrm{IE}, \mathrm{ZP}$, and JK were responsible for study concept and design. $\mathrm{HS}$ and $\mathrm{HJ}$ performed the experiment. ZP, AE, and $\mathrm{HS}$ analyzed and interpreted the data. $\mathrm{AE}$ and IE wrote the manuscript. All authors read and approved the final manuscript.

\section{Funding}

This work was supported by the National Natural Science Foundation of China (Grant 81772046, 81971816).

\section{Availability of data and materials}

The datasets used and/or analyzed during the current study are available from the corresponding author on reasonable request.

\section{Declarations}

\section{Ethics approval and consent to participate}

This prospective observational clinical study was conducted with the approval of the Ethics Committee of Zhongnan Hospital of Wuhan University, at the general ICU of Zhongnan Hospital of Wuhan University, Hubei Province, China. All performed procedures on animals were previously reviewed and approved by the Animal Care and Use Committee of Wuhan University.

\section{Consent for publication}

Not applicable.

\section{Competing interest}

IE is the developer of P-MCP. The other authors declare that they have no competing interests.

\section{Author details \\ ${ }^{1}$ Department of Critical Care Medicine, Zhongnan Hospital, Wuhan University, Wuhan, Hubei Province, China. ${ }^{2}$ School of Medicine, University of California, San Francisco, CA, USA. ${ }^{3}$ Center of Critical Care Nephrology, Department of Critical Care Medicine, University of Pittsburgh Medical Center, Pittsburgh, PA, USA. ${ }^{4}$ Amitabha Medical Center, Santa Rosa, CA, USA.}

Received: 28 December 2020 Accepted: 8 March 2021

Published online: 18 March 2021

References

1. Uchino S, Kellum JA, Bellomo R, Doig GS, Morimatsu H, Morgera S, et al. Acute renal failure in critically ill patients: a multinational, multicenter study. JAMA. 2005;294:813-8.

2. Bagshaw SM, Uchino S, Bellomo R, Morimatsu H, Morgera S, et al. Septic acute kidney injury in critically ill patients: clinical characteristics and outcomes. CJASN. 2007:2:431-9. 
3. Bouchard J, Acharya A, Cerda J, Maccariello ER, Madarasu RC, Tolwani AJ, et al. A prospective international multicenter study of AKI in the intensive care unit. CJASN. 2015:10:1324-31.

4. Hoste EA, Bagshaw SM, Bellomo R, Cely CM, Colman R, et al. Epidemiology of acute kidney injury in critically ill patients: the multinational AKIEPI study. Intensive Care Med. 2015;41:1411-23.

5. Rudd KE, Johnson SC, Agesa KM, Shackelford KA, Tsoi D, Kievlan DR, et al. Global, regional, and national sepsis incidence and mortality, 1990-2017: analysis for the Global Burden of Disease Study. Lancet. 2020;395:200-1.

6. Bagshaw SM, George C, Bellomo R, Committee ADM. Early acute kidney injury and sepsis: a multicentre evaluation. Crit Care. 2008;12:R47.

7. Mehta RL, Bouchard J, Soroko SB, Ikizler TA, Paganini EP, Chertow GM, et al. Sepsis as a cause and consequence of acute kidney injury: program to improve care in acute renal disease. Intensive Care Med. 2011;37:241-8.

8. Tandukar S, Palevsky PM. Continuous renal replacement therapy: who, when, why, and how. Chest. 2019;155(3):626-38.

9. Singbartl K, Formeck CL, Kellum JA. Kidney-immune system crosstalk in AKI. Semin Nephrol. 2019;39:96-106.

10. Tanaka T, Narazaki M. Kishimoto T immunotherapeutic implications of IL-6 blockade for cytokine storm. Immunotherapy. 2016;8:959-70.

11. Bozza FA, Salluh Jl, Japiassu AM, Soares M, Assis EF, Gomes RN, et al. Cytokine profiles as markers of disease severity in sepsis: a multiplex analysis. Crit Care. 2007;11:R49.

12. Kellum JA, Kon L, Fink MP, Weissfeld LA, Yealy DM, Pinsky MR, et al. Understanding the inflammatory cytokine response in pneumonia and sepsis: results of the Genetic and Inflammatory Markers of Sepsis (GenIMS) Study. Arch Intern Med. 2007;167(15):1655-63.

13. Wu HP, Chen CK, Chung K, Tseng JC, Hua CC, Liu YC, et al. Serial cytokine levels in patients with severe sepsis. Inflamm Res. 2009;58:385-93.

14. Mera S, Tatulescu D, Cismaru C, Bondor C, Slavcovici A, Zanc V, et al. Multiplex cytokine profiling in patients with sepsis. APMIS. 2011;119:155-63.

15. Kellum JA, Pike F, Yealy DM, Huang DT, Shapiro NI, Angus DC, et al. Relationship between alternative resuscitation strategies, host response and injury biomarkers, and outcome in septic shock. Critical Care Med. 2017:45(3):438-45.

16. Hashizume M. Outlook of IL-6 signaling blockade for COVID-19 pneumonia. Inflamm Regen. 2020;40:24-31.

17. Buckley LF, Wohlford GF, Ting C, Alahmed A, Van Tassell BW, Abbate A, et al. Role for anti-cytokine therapies in severe coronavirus disease 2019 Critical Care Explor. 2020;2:e0178.

18. Dumic J, Dabelic S, Flögel M. Galectin-3: an open-ended story. Biochim Biophys Acta. 2006;1760:616-35.

19. Henderson NC, Sethi T. The regulation of inflammation by galectin-3. Immunol Rev. 2009;230:160-71.

20. ten Oever J, Giamarellos-Bourboulis E, Van De Veerdonk F, Stelma F, Simon $A$, Janssen $M$, et al. Circulating galectin-3 in infections and non-infectious inflammatory diseases. Eur J Clin Microbiol Infect Dis. 2013;32:1605-10.

21. Mueller T, Leitner I, Egger M, Haltmayer M, Dieplinger B. Association of the biomarkers soluble ST2, galectin-3 and growth-differentiation factor-15 with heart failure and other non-cardiac diseases. Clin Chim Acta. 2015;445:155-60.

22. Dieplinger B, Egger $M$, Leitner I, Firlinger F, Poelz W, Lenz K, et al. Interleukin 6, galectin 3, growth differentiation factor 15, and soluble ST2 for mortality prediction in critically ill patients. J Crit Care. 2016:34:38-45.

23. O'Seaghdha CM, Hwang SJ, Ho JE, Vasan RS, Levy D, Fox CS. Elevated galectin-3 precedes the development of CKD. JASN. 2013;24:1470-7.

24. Drechsler C, Delgado G, Wanner C, Blouin K, Pilz S, Tomaschitz A, et al. Galectin-3, renal function, and clinical outcomes: results from the LURIC and 4D studies. JASN. 2015:26:2213-21.

25. Rebholz CM, Selvin E, Liang M, Ballantyne CM, Hoogeveen RC, Aguilar $D$, et al. Plasma galectin-3 levels are associated with the risk of incident chronic kidney disease. Kidney Int. 2018;93:252-9.

26. Kim H, Hur M, Moon HW, Yun YM, Di Somma S. Multi-marker approach using procalcitonin, presepsin, galectin-3, and soluble suppression of tumorigenicity 2 for the prediction of mortality in sepsis. Ann Intensive Care. 2017;7:27.

27. von Ballmoos MW, Likosky DS, Rezaee M, Lobdell K, Alam S, Parker D, et al. Elevated preoperative galectin-3 is associated with acute kidney injury after cardiac surgery. BMC Nephrol. 2018;19:280.
28. Prud'homme M, Coutrot M, Michel T, Boutin L Genest M, Poirier F, et al. Acute kidney injury induces remote cardiac damage and dysfunction through the galectin-3 pathway. JACC Basic Transl Sci. 2019:4:717-32.

29. Mishra BB, Li Q, Steichen AL, Binstock BJ, Metzger DW, Teale JM, et al. Galectin-3 functions as an alarmin: pathogenic role for sepsis development in murine respiratory tularemia. PLoS ONE. 2013;8:e59616.

30. Ferreira RG, Rodrigues LC, Nascimento DC, Kanashiro A, Melo PH, Borges VF, et al. Galectin-3 aggravates experimental polymicrobial sepsis by impairing neutrophil recruitment to the infectious focus. J Infect. 2018;77:391-7

31. Henderson NC, Mackinnon AC, Farnworth SL, Kipari T, Haslett C, Iredale JP, et al. Galectin-3 expression and secretion links macrophages to the promotion of renal fibrosis. Am J Pathol. 2008;172:288-98.

32. Sasaki S, Bao Q, Hughes RC. Galectin-3 modulates rat mesangial cell proliferation and matrix synthesis during experimental glomerulonephritis induced by anti-Thy11 antibodies. J Pathol. 1999;187:481-9.

33. Nishiyama J, Kobayashi S, Ishida A, Nakabayashi I, Tajima O, Miura S, et al. Up-regulation of galectin-3 in acute renal failure of the rat. Am J Pathol. 2000;157:815-23.

34. Dang Z, MacKinnon A, Marson LP, Sethi T. Tubular atrophy and interstitial fibrosis after renal transplantation is dependent on galectin-3. Transplantation. 2012;93:477-84.

35. Fernandes Bertocchi AP, Campanhole G, Wang PHM, Gonçalves GM, Damião MJ, Cenedeze MA, et al. A role for galectin-3 in renal tissue damage triggered by ischemia and reperfusion injury. Transpl Int. 2008;21:999-1007.

36. Kolatsi-Joannou M, Price KL. Winyard, PJ Long, DA Modified citrus pectin reduces galectin-3 expression and disease severity in experimental acute kidney injury. PLoS ONE. 2011;6(e1868):3.

37. Frenay A-RS, Yu L, van der Velde AR, Vreeswijk-Baudoin I, López-Andrés $\mathrm{N}$, van Goor $\mathrm{H}$, et al. Pharmacological inhibition of galectin-3 protects against hypertensive nephropathy. Am J Physiol Renal Physiol. 2015:308:F500-F509.

38. Martínez-Martínez E, Ibarrola J, Fernández-Celis A, Calvier L, Leroy C, Cachofeiro V, et al. Galectin-3 pharmacological inhibition attenuates early renal damage in spontaneously hypertensive rats. J Hypertens. 2018;36:368-76.

39. Calvier L, Martinez-Martinez E, Miana M, Cachofeiro V, Rousseau E, Sádaba JR, et al. The impact of galectin-3 inhibition on aldosterone-induced cardiac and renal injuries. JACC Heart Fail. 2015;3:59-67.

40. Zhang M, Gu Y, Wang H, Zhu P, Liu X, Wu J. Valsartan attenuates cardiac and renal hypertrophy in rats with experimental cardiorenal syndrome possibly through down-regulating galectin-3 signaling. Eur Rev Med Pharmacol Sci. 2016:20:345-54

41. Martinez-Martinez E, Ibarrola J, Calvier L, Fernandez-Celis A, Leroy C, Cachofeiro V, et al. Galectin-3 blockade reduces renal fibrosis in two normotensive experimental models of renal damage. PLoS ONE. 2016;11:e0166272.

42. Li HY, Yang S, Li JC, Fen, JX. Galectin 3 inhibition attenuates renal injury progression in cisplatin-induced nephrotoxicity. Biosci Rep. 2018:38:BSR20181803.

43. Shankar-Hari M, Phillips GS, Levy ML, Seymour CW, Liu VX, Deutschman CS, et al. Developing a new definition and assessing new clinical criteria for septic shock: for the Third International Consensus Definitions for Sepsis and Septic Shock (Sepsis-3). JAMA. 2016;315:775-87.

44. Knaus WA, Draper EA, Wagner DP, Zimmerman JE. APACHE II: a severity of disease classification system. Crit Care Med. 1985;13:818-29.

45. Kellum JA, Lameire N, Aspelin P, Barsoum RS, Burdman EA, Goldstein SL, et al. Kidney Disease: Improving Global Outcomes (KDIGO) Acute Kidney Injury Work Group KDIGO clinical practice guideline for acute kidney injury. Kidney Int Suppl. 2012;2:1-138.

46. Eliaz I, Raz A. Pleiotropic effects of modified citrus pectin. Nutrients. 2019;11(11):2619.

47. Peng ZY, Wang HZ, Srisawat N, Wen X, Rimmelé T, Bishop J, et al. Bactericidal antibiotics temporarily increase inflammation and worsen acute kidney injury in experimental sepsis. Crit Care Med. 2012:40:538-43.

48. Zhou F, Peng ZY, Bishop JV, Cove ME, Singbartl K, Kellum JA. Effects of fluid resuscitation with 09\% saline versus a balanced electrolyte solution on acute kidney injury in a rat model of sepsis. Crit Care Med. 2014;42:e270-8. 
49. Zou KH, O'Malley AJ, Mauri L. Receiver-operating characteristic analysis for evaluating diagnostic tests and predictive models. Circulation. 2007;115:654-7.

50. Huang YT, Lai MY, Kan WC, Shiao CC. Independent Predictive Ability of Procalcitonin of Acute Kidney Injury among Critically III Patients. J Clin Med. 2020;9(6):1939.

51. Chun K, Chung W, Kim AJ, Hyunsook K, Han R, Jae HC, et al. Association between acute kidney injury and serum procalcitonin levels and their diagnostic usefulness in critically ill patients. Sci Rep. 2019:9:4777.

52. Dai X, Zeng Z, Fu C, Zhang S, Cai Y, Chen Z. Diagnostic value of neutrophil gelatinase-associated lipocalin, cystatin $C$, and soluble triggering receptor expressed on myeloid cells-1 in critically ill patients with sepsis-associated acute kidney injury. Crit Care. 2015;19(1):223.
53. Desmedt V, Desmedt S, Delanghe JR, Speeckaert R, Speeckaert MM. Galectin-3 in renal pathology: more than just an innocent bystander? Am J Nephrol. 2016;43:305-17.

54. Garcia-Revilla J, Deierborg T, Venero JL, Boza-Serrano A. Hyperinflammation and fibrosis in severe COVID-19 patients: Galectin-3, a target molecule to consider. Front Immunol. 2020;11:2069.

\section{Publisher's Note}

Springer Nature remains neutral with regard to jurisdictional claims in published maps and institutional affiliations.
Ready to submit your research? Choose BMC and benefit from:

- fast, convenient online submission

- thorough peer review by experienced researchers in your field

- rapid publication on acceptance

- support for research data, including large and complex data types

- gold Open Access which fosters wider collaboration and increased citations

- maximum visibility for your research: over $100 \mathrm{M}$ website views per year

At BMC, research is always in progress.

Learn more biomedcentral.com/submissions 